\section{MS34-P12 From homonuclear metal string complexes to heteronuclear metal string complexes}

Shie-Ming Peng ${ }^{1,2}$, Shao-An Hua ${ }^{1}$, Ming-Chuan Cheng ${ }^{2}$

1. Department of Chemistry, National Taiwan University, Taipei, Taiwan

2. Institute of Chemistry, Academia Sinica, Taipei, Taiwan

email: smpeng@ntu.edu.tw

The study of metal string complexes with 1-D transition metal frameworks began in the early 1990s. Since these complexes provide great insight into multiple metal-metal bonds, and may have potential applications as molecular wires, this field of research has grown in the past 20 years. As such, the electronic structure of the simplest trinuclear complexes, the supporting ligand systems, and single molecular conductance of metal string complexes are discussed. This review will introduce the development of this field and summarize some important results in the newly designed heteronuclear metal string complexes (HMSCs). These molecules may be of great interest in studying the nature of heterometallic electronic effects and molecular electronic applications.

\section{REFERENCES}

[1] Ismayilov RH, Wang WZ, Lee GH, Yeh CY, Hua SA, Song Y, Rohmer MM, Bénard M, S-M Peng Angew. Chem. Int. Ed., 2011, 50, 2045-2048.

[2] M-C Cheng, C-L Mai, C-Y Yeh, G-H Lee and S-M Peng Chem. Commun. 2013, 49, 7938-7940.

[3] M-J Huang, S-A Hua, M-D Fu, G-C Huang, C Yin, C-H Ko, C-K Kuo, C-H Hsu, G-H Lee; K-Y Ho, C-H Wang, Y-W Yang, I-C Chen, S-M Peng, C-h Chen Chemistry-A European Journal 2014, 20(16), 4526-4531.

[4] S-A Hua, M-C Cheng, C-h Chen, and S-M Peng European Journal of Inorganic Chemistry 2015, Micro Review, "From Homonuclear Metal String Complexes to Heteronuclear Metal String Complexes" DOI:10.1002/ejic.201403237.
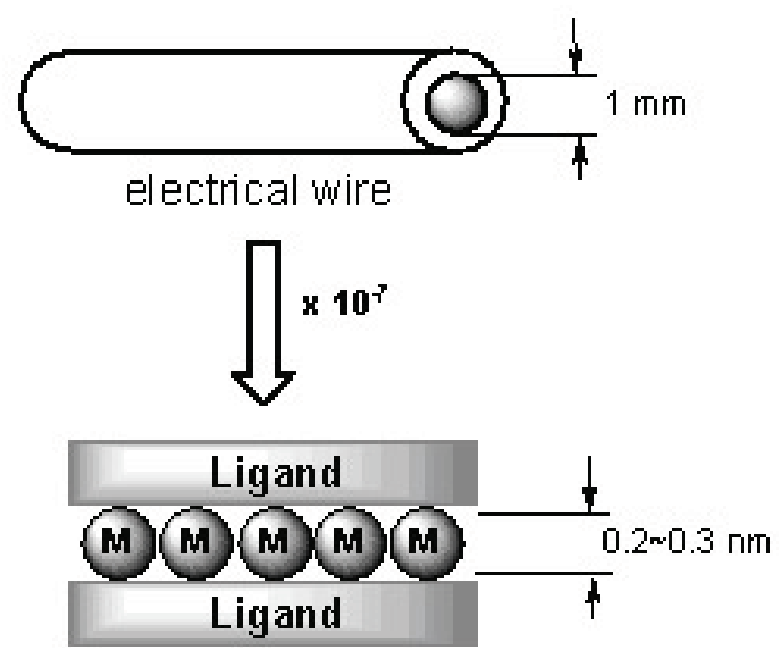

molecular metal wire
MS35. Dynamics in

nanoporous molecular crystals
Chairs: Angiolina Comotti, Len Barbour

\section{MS35-P1 Control of porosity through temperature and pressure}

Jan A. Gertenbach ${ }^{1}$, Simon A. Herbert ${ }^{2}$, Tia Jacobs ${ }^{2}$, Agnieszka Janiak $^{2}$, Len J. Barbour ${ }^{2}$

1. PANalytical B.V., Almelo, The Netherlands

2. Stellenbosch University, Stellenbosch, South Africa

email: jan.gertenbach@panalytical.com

Gaining control of phase transformations offers the possibility of tailoring the properties of polymorphic materials. X-ray powder diffraction is ideally suited to studying such structural modifications, particularly since the bulk material is analysed, allowing the averaged structural features of the material to be correlated with its bulk physical properties, in this case the porosity. In addition, rapid X-ray diffraction data collection allows the determination of intermediate phases, onset points of reactions and information about the reversibility of processes involved.

The material studied here exists in four distinct polymorphic forms, each porous to a differing extent. Control of the desired polymorph, and hence the desired porosity is achieved by manipulation of temperature and pressure. The X-ray diffractograms were modelled by Rietveld refinement using the HighScore Plus software ${ }^{2}$ to study the structural processes during the phase transformations. The physical properties determined by sorption measurements were modelled using Partial Least Squares Regression (PLSR) analysis, and this data compared to the output from the Rietveld structural study.

1. see for example Herbert, S.A. et al. J. Am. Chem. Soc. (2013) 17, 6411-6414.

2. Degen, T. et al. Powder Diffr. (2014) 29, S13-S18.

Keywords: porosity, Rietveld, polymorph

Figure 1. An electric wire and a miniature molecular wire.

Keywords: Metal String Complexes 